\title{
Maternal Outcome of Anemic Pregnant Mother at Private Hospitals in Dhaka City
}

\author{
Muhammad Zahangir *1
}

\section{Abstract}

Introduction: The study carried out among the pregnant women who had anemia during pregnancy with the objectives to determine their maternal outcome at private hospitals in Dhaka city. Materials and Methods: The total sample size was 110. Data was collected by interviewing the respondents with a structured pre-tested questionnaire. The study was conducted in pregnant women with anemia at or after 28 weeks of gestation and had delivered at Obstetrics Department of Ad-Din Barrister Rafique ul-Huq Hospital, Jurain and Bashundhara Ad-Din Medical College Hospital South Keranigonj. Results: Most of the respondents (38.2\%) belonged to the age group between 16-20 years. The mean age was $23.74 \pm 5.127$ years. Almost (49.1\%) up to primary \& (38.2\%) were up to secondary/higher secondary level. Most of the respondents were homemaker (87.3\%); Monthly income means was 19340.91 12459.647. Most (90.9\%) of the respondents had received $A N C$ and $79.1 \%$ respondent's hemoglobin level was below $10 \mathrm{gm}$. /dl. Among them $90.9 \%$ of the respondent's fetal outcome were healthy \& alive baby. More than half (51.8\%) of the respondent's baby were $\leq 2.5 \mathrm{~kg}$ birth weight. Study also shows that $55.5 \%$ respondents had anemia after delivery, $28.2 \%$ had sickness and $22.7 \%$ were sulfured with complications after delivery. There was a significant relationship with low birth weights $(L B W)$ to less high education. Conclusion: All women should be given advice regarding diet in pregnancy with details of foods rich in iron. Dietary changes alone are not sufficient to correct an existing iron deficiency in pregnancy and iron supplements are necessary.

Keywords: Anemic pregnant, Hemoglobin level, Gestational age, maternal outcome.

Number of Tables: 05; Number of Figures: 03; Number of References: 25; Number of Correspondences: 05.

*1. Corresponding Author: Dr. Muhammad Zahangir

Associate Professor

Department of Anesthesia

Bashundhara Ad-Din Medical College Hospital,

Keranigong, Dhaka.

Email: zahangir.ibmchr@gmail.com

Mobile: 01890930205

\section{Introduction:}

Anemia is recognized as a major public health problem, affecting over 1.2 billion people in developed and developing countries ${ }^{1}$. The prevalence is highest in developing countries. Maternal anemia is a common problem in pregnancy in developing countries like Bangladesh. According to WHO anemia is defined as a Hemoglobin level of $<11 \mathrm{gm}$. /dl. in adult. In many regions, 2 anemia due to iron deficiency has serious health and functional consequences and the most of its nutritional component is controllable. It is estimated that 1200 million people are anemic globally. The consequences of anemia are reduced level of energy and poor pregnancy outcome (miscarriage, still birth, prematurity, low birth, perinatal mortality). Some studies have shown a strong association between low $\mathrm{Hb}$ before delivery and adverse outcome $^{2}$.

Worldwide anemia is a major cause of morbidity and mortality, mainly due to malnutrition \& infection in the developing countries. Correction of this continues to pose an apparently insurmountable challenge, but for the economic \& social reasons rather than back of medical knowledge ${ }^{3}$. Total prevalence of anemia in the world is $30 \%$ of estimated world population of 5000 (1985) million people. Young children \& pregnant women are mostly affected globally. Regions with higher prevalence of anemia are South Asia \& Africa ${ }^{4}$.

Clinically, anemia is any hemoglobin $(\mathrm{Hb})$ level $<10.5 \mathrm{~g} / \mathrm{dL}$ regardless of age; however, the World Health Organization (WHO) recommends maintaining $\mathrm{Hb}$ levels $\geq 11.0 \mathrm{~g} / \mathrm{dL}$ during pregnancy. Anemia in pregnancy develops when physiological changes reduce $\mathrm{Hb}$ concentrations. These changes are mainly a result of nutritional deficiencies of which iron deficiency is the most common cause. Iron deficiency is the major cause for anemia in pregnant women, accounting for $\sim 75 \%$ of all pregnancy related anemia 5 .

Maternal mortality is higher in rural areas and among poorer and less educated communities. Adolescents face a higher risk of complications and death as a result of pregnancy than older women ${ }^{6}$.

The reduction of maternal and child death is a high priority for the international community, especially in view of the increased attention on the Millennium Development Goals 4 and 5. The South East Asia region accounts for almost one-third of global mortality in neonates and children under 5 years of age. Despite of wide disparities in socio-economic and health indicators, many countries in this region are unlikely to reach Millennium Development Goals 4 and $5^{7}$.

Bangladesh has made commendable progress in achieving MDG 4 and 5. Since 1990, there has been a remarkable reduction in 
maternal and child mortality, with an estimated $57 \%$ reduction in child mortality and $66 \%$ in maternal mortality. Bangladesh is on track for achieving MDG 4 and 5, progress in universal access to reproductive health is not yet at the required pace to achieve the targets set for 2015 . In addition, Bangladesh needs to further augment activities to get better newborn health and promote skilled attendance at birth. In South East Asia, child and infant mortality has reduced considerably but the neonatal mortality rate is still high. Newborn care is immense importance for the proper development and healthy life of a baby. A study in Bangladesh revealed an urgent need to educate mothers, and train traditional birth attendants and health workers on clean delivery practices, early neonatal care and prevention of delivery complications ${ }^{8}$.

Globally, the mean blood hemoglobin concentration was $11.1 \mathrm{~g} / \mathrm{d} l$. Anemia resulting from iron deficiency adversely affects cognitive and motor development, causes fatigue and low productivity and, when it occurs in pregnancy, may be associated with low birth weight and increased risk of preterm delivery. The mechanisms causal to these effects are unknown, but they may be related to reduce oxygen delivery to the placenta and fetus, increased rates of infection, or adverse effects of iron deficiency on brain development ${ }^{8,9,10}$. Anemia is one of the most prevalent nutritional deficiency problems affecting pregnant women. The prevalence of anemia in pregnancy differs significantly because of variations in socioeconomic conditions, lifestyles, and health-seeking behaviors across different cultures $^{11,12}$.

Study in Turkey reported that approximately $90 \%$ of adolescent pregnancies are unplanned, and a great amount unplanned adolescent pregnancies are unintended. Adolescent pregnancy is associated with high risk of serious obstetric complications and poor neonatal outcomes such as abortion, preterm delivery, preeclampsia, significant anemia, and mechanical and operative delivery ${ }^{13}$.

The major complication in young mothers are thought to be high blood pressure, iron deficiency anemia, cephalopelvic disproportion and low birth weight ${ }^{14}$.

Adolescent girls are at a risk of having anemia in pregnancy, which is considered to be mainly responsible for the prevailing high maternal mortality and high incidence of low birth weight deliveries in India ${ }^{15}$.

Study shows that Anemia was the commonest (50\%) form of maternal complication, followed by pregnancy-induced hypertension (26\%), postpartum hemorrhage (30\%), pre $\neg$ term labor $(18 \%)$, prolonged labor $(14 \%)$, obstructed labor $(12 \%)$, and failure of or inadequate lactation $(10 \%)^{16}$.

The United States, approximately 52 out of 1,000 adolescent girls gave birth while in the United Kingdom there were about 30 births in 1,000 adolescent girls. It has been reported that $51 \%$ of adolescent pregnancies end in live birth. Different reports suggested that adolescent pregnancies are associated with increased incidence of medical and obstetrical complications including anemia, pregnancy-induced hypertension and prematurity. Whereas the incidence of preterm labor was significantly higher in the adolescent pregnancy group (14.6\% vs $8 \%$, respectively; Concerning labor performance in both the groups, the incidence of caesarean section was significantly lower (7.1\% vs $16.8 \%)$ and the incidence of spontaneous delivery was significantly higher $(61.8 \%$ vs $52.6 \%)$ with a significant increase in the duration of second stage of labor $(26 \pm 26.5$ vs $12.6 \pm 17.3)$ in the adolescent pregnancy. This finding is supported by many authors who have suggested that adolescent pregnancies are associated with increased risk of preterm labor ${ }^{17}$.

In developing countries, most anemia' are due to nutritional iron deficiency, although some other causes include malaria and parasitic infections. Adolescents are at increased risk of iron deficiency because they are still growing and at the onset of menstruation. The analysis results show that more than fifty percent adolescent suffer pregnancy complications whereas only eight percent female suffer those complications that experience conception at age 20 years and later. The maximum adolescents suffer anemia complication during the time of pregnancy. About 98 percent adolescent suffer delivery complications like eclampsia, lengthy delivery, excess hemorrhage, and delay in delivery of placenta whereas only 16 percent suffer these complications that are pregnant at age 20 years and later ${ }^{18}$.

A study in USA reveals girls under 15 have a maternal mortality rate 3 times that of women aged 20-24 years. At the other end of the scale, the risk associated with child bearing begins to rise again after the age of 30 or 35 years ${ }^{19}$. Study on teenage child bearing in the United States showed that the negative consequences of teenage child bearing were severe. Teen mothers are less likely to receive timely prenatal care and they have higher rate for certain risk factors for poor pregnancy outcomes ${ }^{16}$.

A north Indian study also shown that the prevalence of anemia is high $69(46 \%)$ among teenage mothers, which occurs due to low intake of dietary iron ${ }^{20}$.

In Ghana (2017) by Anlaakuu Study found that out of the 316 participants, $129(40.8 \%)$ were found to be anemic $(\mathrm{Hb}$ $<11.0 \mathrm{~g} / \mathrm{dl}$ ) at the time of their first ANC visit (mean $\mathrm{Hb}$ : $11.21 \mathrm{~g} / \mathrm{dl}$, range $6.8-15.1 \mathrm{~g} / \mathrm{dl})$. Seventy-nine $(61.2 \%)$ of them had mild anemia (Hb 9.0-10.9 g/dl), 48 (37.2\%) had moderate anemia ( $\mathrm{Hb} 7.0-8.9 \mathrm{~g} / \mathrm{dl})$ whilst $2(1.6 \%)$ had severe anemia $(\mathrm{Hb}<7.0 \mathrm{~g} / \mathrm{dl})$. During their most recent ANC visit, the prevalence of anemia was found to be similar to that of the first visit with 131 (41.5\%) of them being anemic [mean $\mathrm{Hb}: 11.24 \mathrm{~g} / \mathrm{dl}$, range $8.10-14.5 \mathrm{~g} / \mathrm{dl}$ ]. The hemoglobin levels however improved significantly during the most recent visit compared to the first with none of the women being severely anemic $(\mathrm{Hb}<7.0 \mathrm{~g} / \mathrm{dl})$. The prevalence of moderate anemia reduced from $37.2 \%$ (CI 28.9-46.2) during the first visit to $19.1 \%(12.7-26.9)$ 
during the most recent visit, a reduction of $48.7 \%{ }^{21}$.

Bangladesh; Institute of Nutrition and FOOD science, University of Dhaka by Jahan K. showed that many gaps in our knowledge about the adverse effects of maternal anemia and iron deficiency on pregnancy outcome. Our study showed significant association between anemia and preterm birth and pre-eclampsia, still larger studies with more cases showing this association with severe maternal anemia carries significant risk of hemorrhage and infection in mother and small for gestational age infants as well as low APGAR score and high prenatal mortality. However, there is substantial evidence that maternal iron deficiency anemia increases the risk of preterm delivery and subsequent low birth weight, certainly, iron supplements improves the iron status of the mother during pregnancy and during the post-partum period, even in women who enter pregnancy with reasonable iron stores ${ }^{22}$.

The United States. MMWR Morb Mortal Wkly Rep. Study showed that the major concern about the adverse effects of anemia on pregnant women is the belief that the population is at greater risk of perinatal mortality and morbidity. Maternal mortality in selected developing countries ranges from 27 (India) to 194 (Pakistan) deaths per 10,000 live births for example in a large Indonesian study the maternal mortality rate for women with a hemoglobin concentration $<10 \mathrm{gm}$./dl was 70.00/10000 deliveries compared with 19.7/10000 deliveries for non-anemic women ${ }^{23}$.

The Indian study effect of maternal iron deficiency anemia on fetal outcome by Russia U study found that the relation between maternal anemia and birth weight has been reviewed more extensively elsewhere in the issue. In severe studies, AV staped association was observed between maternal hemoglobin concentration and birth weight. Low birth weight of anemic women has been reported in several studies ${ }^{24}$.

Human nutrition and Dietetics by Hallberg L. study found that There is a substantial among of evidence showing that maternal iron deficiency anemia early in pregnancy can result in low birth weight subsequently to preterm delivery for example, Wilson women who were first diagnosed with anemia at 13-24 wk. of gestation had a 1.18-1.75-fold higher risk of preterm birth, low birth weight and perinatal mortality $^{25}$.

\section{Materials and Methods:}

This cross sectional study was carried out at Obstetric Department of Ad-Din Barrister Rafique ul-Huq Hospital, Jurain, Dhaka and Bashundhara Ad-Din Medical College Hospital, South Keranigong, Dhaka. The study population was pregnant women with anemia at or after 28 weeks of gestation who delivered at these two private hospitals in Dhaka city. The sample size was 110 . There was purposive selection of sample during study period. Data was collected by face to face interview of the respondents with a structured pretested questionnaire. All the collected data were organized and analyzed with the help of the software SPSS for windows.

\section{Results:}

In this study 110 anemic pregnant women were studied in two hospitals and the results shows highest $38.2 \%$ of pregnant women have found in the age group 16-20 years and mean $( \pm \mathrm{SD}) 23.74( \pm 5.127)$. Respectively second and third highest $30 \%$ and $20.9 \%$ in the age group 21-25 years and 26-30 years. Majority (97.3\%) was Muslims. About half (49.1\%) of the respondent's educational level was up to primary level, $38.2 \%$ of the respondents were up to secondary/higher secondary and $4.5 \%$ were up to graduate and above. Most (87.3\%) of the respondents were homemaker by occupation and $12.7 \%$ respondents in business and in job. The mean $( \pm \mathrm{SD})$ of monthly family income was taka $19340.91( \pm 12459.647)$. More than one third $(37.3 \%)$ of the respondents were from low income family followed by $40.9 \%$ by middle income and high income family (21.8\%) (Table I).

Table-I: Socio-demographic characteristics of the respondents $(n=110)$.

\begin{tabular}{lcc}
\hline Variables & Frequency & Percent \\
\hline Age groups & 42 & \\
16-20 years & 33 & 38.2 \\
21-25 years & 23 & 30.0 \\
26-30 years & 12 & 20.9 \\
31-38 years & & 10.9 \\
\hline Religion & 107 & \\
Muslim & 3 & 97.3 \\
Hindu & & 2.7 \\
\hline Educational level & 8 & \\
Illiterate & 1 & 7.3 \\
Non formal education & 54 & .9 \\
Primary level & 42 & 49.1 \\
Secondary/higher secondary & 5 & 38.2 \\
Graduate \& above & & 4.5 \\
\hline Occupation of respondents & 96 & 87.3 \\
Homemaker & 14 & 12.7 \\
Business \& job & & \\
\hline Monthly income (in Tk) & 41 & 37.3 \\
Low (5000-10000) & 45 & 40.9 \\
Middle (10001-20000) & 24 & 21.8 \\
High ( $>20000)$ & 110 & 100.0 \\
\hline Total & & \\
\hline
\end{tabular}

The mean age at marriage was $17.79 \pm 3.400$. More than half $(55.5 \%)$ of the respondents got married in the age interval of 16-20 years and about half $(47.3 \%)$ of the respondents had concept 13-19 years' age at first time. The mean age at first time of concept 20.12 \pm 3.173 (Table II).

Table-II: Distribution of the respondents by age at marriage $\&$ first time concept $(n=110)$.

\begin{tabular}{lcc}
\hline Variables & Frequency & Percent \\
\hline Age at marriage & & \\
10- 15 years & 28 & 25.5 \\
16-20 years & 61 & 55.5 \\
21-25 years & 17 & 15.5 \\
26-27 years & 4 & 3.6 \\
\hline Age at first time concept & 52 & \\
13- 19 years & 45 & 47.3 \\
20-24 years & 13 & 40.9 \\
25-29 years & $\mathbf{1 1 0}$ & 11.8 \\
\hline Total & & $\mathbf{1 0 0 . 0}$ \\
\hline
\end{tabular}

Figure no. 1 shows that more than two third (67.3\%) of the respondents had knowledge about anemia but $32.7 \%$ of the respondents had no knowledge about this. 

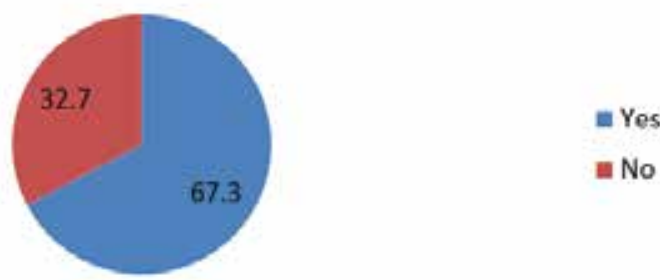

Figure 1: Distribution of the respondents by knowledge anemia $(n=110)$.

Figure 2 shows that most $(90.9 \%)$ of the respondents had received ANC during pregnancy, only $9.1 \%$ respondents had no received $\mathrm{ANC}$ during pregnancy

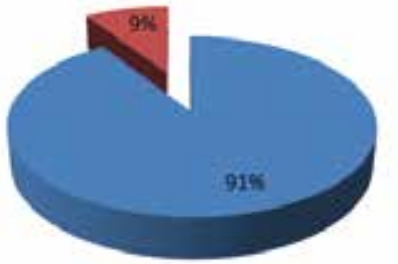

wes

$=$ No

Figure 2: Distribution of the respondents by received ANC during pregnancy $(\mathrm{n}=110)$.

Most (78.2\%) of the respondents was gestational age of full term, $16.4 \%$ were before term and only $5.5 \%$ were postdated of present baby. It also shows that past of obstetric history $93.1 \%$ had alive baby. A large percentage hemoglobin level of respondents had $(66.4 \%)$ by 6-7.9 gm. /dl (Table III).

Table-III: Distribution of the respondents by gestational age, past obstetric history and Hb level $(n=110)$.

\begin{tabular}{lcc}
\hline Variables & Frequency & Percent \\
\hline Gestational age & 86 & 78.2 \\
Full term & 18 & 16.4 \\
Before term & 6 & 5.5 \\
Postdated & & \\
Obstetric history & 110 & 93.1 \\
Alive baby & 6 & 5.1 \\
Dead after birth & 1 & 0.8 \\
Still birth & 1 & 0.8 \\
Abortion & & \\
Hb level & 23 & 20.9 \\
10-10.9 gm./dl & 73 & 66.4 \\
8-9.9 gm./dl & 14 & 12.7 \\
6-7.9 gm./dl & $\mathbf{1 1 0}$ & $\mathbf{1 0 0 . 0}$ \\
\hline Total & & \\
\hline
\end{tabular}

Among them $90.9 \%$ of the respondent's fetal outcome were health \& alive baby only $9.1 \%$ were alive but sick baby. More than half $(51.8 \%)$ of the respondent's baby were 2.0-2.5 $\mathrm{kg}$ birth weight and $48.2 \%$ baby were more than 2.5 $\mathrm{kg}$ birth weight (Table IV).

Table- IV: Distribution of the respondents by maternal outcome $(n=110)$.

\begin{tabular}{lcc}
\hline Variables & Frequency & Percent \\
\hline Fetal outcome & 100 & 90.9 \\
Healthy \& alive & 10 & 9.1 \\
Alive but sick & & \\
\hline Birth weight & 57 & 51.8 \\
$2.0-2.5 \mathrm{~kg}$ & 53 & 48.2 \\
$>2.5 \mathrm{~kg}$ & $\mathbf{1 1 0}$ & $\mathbf{1 0 0 . 0}$ \\
\hline Total & & \\
\hline
\end{tabular}

Figure 3 shows that maximum $(83.6 \%)$ of the respondents were Lucs mode of delivery and $16.4 \%$ were NVD delivery.

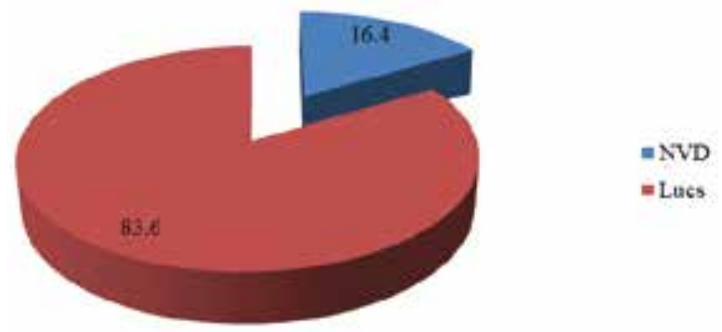

Figure-3: Distribution of the respondents by mode of delivery $(n=110)$.

From Table-V shows that more than half $(55.5 \%)$ of the respondents had anemic status after delivery, 28.2\% were sickness after delivery and $22.7 \%$ of the respondents were complication after delivery.

Table- V: Distribution of the respondents by condition of mother after delivery $(n=110)$.

\begin{tabular}{lcc}
\hline $\begin{array}{l}\text { Condition of mother } \\
\text { after delivery }\end{array}$ & Frequency & Percent \\
\hline Sickness & 31 & 28.2 \\
Anemic & 61 & 55.5 \\
Complication & 25 & 22.7 \\
\hline
\end{tabular}

\section{Discussion:}

The present study was conducted with the objective to find out the pregnancy outcome of anemic mother in a private hospital in Dhaka city. The mean age was $\pm \mathrm{SD}=$ $23.74 \pm 5.127$ years, $38.2 \%$ of the respondents were in age group between 16-20 years. Most of the respondents $(97.3 \%)$ were religion Islam whereas only $2.7 \%$ were Hindu. About half (49.1\%) of the respondent's educational level was up to primary level \& $38.2 \%$ were up to secondary/higher secondary level Most $(87.3 \%)$ of the respondents were homemaker by occupation and $12.7 \%$ respondents in business and in job. The mean $( \pm \mathrm{SD})$ of monthly family income was taka $19340.91( \pm 12459.647)$. More than one third $(37.3 \%)$ of the respondents were from low income family followed by $40.9 \%$ by middle income and high income family (21.8\%). As per Bangladesh Demographics profile 2013, majority $(89.5 \%)$ of the people in Bangladesh are Muslims which is nearly consistent with this study ${ }^{9}$.

In presents study found that mean age at marriage was $17.79 \pm 3.400$. More than half $(55.5 \%)$ of the respondents got married in the age interval of 16-20 years and about half $(47.3 \%)$ of the respondents had concept 13-19 years' age at first time. The mean age at first time of concept 20.12 \pm 3.173 . (Table II). Bangladesh population and Housing census 2011 found the mean age at marriage was 17.5 years which is similar to this study. Remarkably, their peek age at 1 st delivery was around the age of 20 years. The mean age of first child birth was 20.67 years with standard deviation (SD) of \pm 2.15 year. Lowest age was 14 years and highest was 30 years. Bangladesh demographic profile 
index mundi 2013, found mean age at 1 st delivery was 18.1 years which is almost similar to this study ${ }^{9,10}$.

Regarding knowledge on anemia found that more than two third $(67.3 \%)$ of the respondents had knowledge about anemia but $32.7 \%$ of the respondents had no knowledge about this. Most (90.9\%) of the respondents had received ANC during pregnancy. These findings were consistent with the findings by Acheampong K. et al. (2018) Ghana. International Journal of Health Sciences \& Research ${ }^{11}$.

From study showed that gestational age most $(78.2 \%)$ of the respondents' gestational age of full term, $16.4 \%$ were before term and only $5.5 \%$ were postdated of present baby. Distribution of past obstetric history. Among them maximum (93.1\%) of the respondents had alive baby. Hemoglobin level shows that $20.9 \%$ of the respondents had 10-10.9 gm. /dl of Hb level, 66.4\% had 8-9.9 gm. /dl and rest $12.7 \%$ of the respondents had 6-7.9 gm. /dl of Hb level. Among them $90.9 \%$ of the respondent's fetal outcome were health $\&$ alive baby only $9.1 \%$ were alive but sick baby and $69.1 \%$ of the respondents had no problem of new born but $15.5 \%, 11.8 \%$ had respiratory distress, Jaundice and rest $3.6 \%$ had fever. Only $12.7 \%$ of the respondents had congenital anomaly of newborn otherwise $87.3 \%$ had no congenital anomaly of newborn. More than half $(51.8 \%)$ of the respondent's baby were $2.0-2.5 \mathrm{~kg}$ birth weight and $48.2 \%$ baby were more than $2.5 \mathrm{~kg}$ birth weight. These findings were nearly consistent with the findings of Adolescent Pregnancy Complication and Wastage in Bangladesh. Journal of Nepal Pediatric. Society, 2010 by Rahman MM, Hasan M, Akhter S, Sultana $\mathrm{P}^{12}$.

This study also found that $83.6 \%$ of the respondents mode of delivery were Lucs, more than half $(55.5 \%)$ of the respondents had anemic status after delivery, 28.2\% were sickness after delivery and $22.7 \%$ of the respondents were complication after delivery (Table-V).

\section{Conclusion:}

From this study it is revealed that majority anemic women belonged to teenage age group. This study is a small sample size study; further studies with large sample size well establish the actual factors for anemic pregnant women. Nevertheless, our results provide the basis for taking necessary measures to aware the mass population and thereby prevent and control anemia in pregnancy.

Conflict of Interest: None.

\section{Acknowledgement}

We are thankful to the nursing staffs of Ad-din Barrister Rafique-ul Huq Hospital and Bashundhara Ad-din Medical College Hospital, DHAKA.

\section{References:}

1. Viteri FE. The consequences of iron deficiency and anemia in pregnancy. In: Nutrient regulation during pregnancy, Lactation and infant growth. L. Alien, J. King and B. Lonnerdal. Eds. 2014; 121-133.
2. WHO. National strategies for overcoming micronutrient malnutrition document EFI 1991; 89:27. Executive Board, 89 th session.

3. Sifakis $\mathrm{S}$, Pharmakides G. Anemia in pregnancy. Ann N Y Acad Sci. 2016; 900(1):125-136.

https://doi.org/10.1111/j.1749-6632.2000.tb06223.x

PMid:10818399

4. WHO/UNICEF "International on Health education for school age children". WHO/UNICEF/HED/861, Geneva 1985: 1.

5. Institute of Medicine (US) Standing Committee on the Scientific Evaluation of Dietary Reference Intakes and its Panel on Folate, Other B Vitamins, and Choline. Dietary Reference Intakes for Thiamin, Riboflavin, Niacin, Vitamin B6, Folate, Vitamin B12, Pantothenic Acid, Biotin, and Choline. Washington (DC): National Academies Press (US). 2018; 18: 563.

6. WHO. World Health Statistics 2011 [Internet]. WHO, 2012.

7. Bajwa SK, Bajwa SJ, Kaur J, Singh K, Kaur J. Is Intensive Care the Only Answer for High Risk Pregnancies in Developing $\mathrm{Na}$ ons? J Emerg Trauma Shock. 2010; 3(4):33.

https://doi.org/10.4103/0974-2700.70752

PMid:21063554 PMCid:PMC2966564

8. Berman P. Organization of ambulatory care provision: a critical determinant of health system performance in developing countries. Bulletin of World Health Organization. 2013; $791-802$.

9. Bangladesh Demographics profile; 2013.

10. Bangladesh population and Housing census; 2011.

11. Mulugeta M, Addis Z, Alem M, Enawgaw B. "Prevalence and Predictors of Maternal Anemia during Pregnancy in Gondar, Northwest Ethiopia: An Institutional Based Cross-Sectional Study," Anemia. 2014: 2302-2914.

https://doi.org/10.1155/2014/108593

PMid:24669317 PMCid:PMC3942101

12. Zehra T, Khan RA, Qadri F. Anemia in Pregnancy Study at Karachi in a Tertiary. Care Centre. American Journal of Phytomedicine and Clinical Therapeutics. 2017: 1224-1233.

13. Candan D, Nil gun O, Yuksel ON. Adolescent Pregnancies: Maternal and Fetal Outcomes. The New Journal of Medicine. 2010; 27: 113-116.

14. Chabra S. Perinatal outcome in Teenage Mothers. The Journal of Obstetrics and Gynecology of India. 1991. 41(1): 30-32.

15. Fraser AM, Brockert JE, Ward RH. Association of young maternal age with adverse reproductive outcomes NEJM. 2015; 332:1113.

https://doi.org/10.1056/NEJM199504273321701

PMid:7700283 
16. Sultana N, Begum SC, Parvin T, Huq SR. Teenage pregnancy and it's outcome in Bangladesh: Has the situation improved? 2017.

17. A1-Tamahi M, Saleh S. Outcome of adolescent pregnancy at a university hospital in Jordan Arch Gynecology Obstetric. 2016; 273: 207-210.

https://doi.org/10.1007/s00404-005-0055-5

PMid:16205933

18. Rahman MM, Hasan M, Akter S, Sultana P. Adolescent Pregnancy Complication and Wastage in Bangladesh. Journal of Nepal Pediatric. Society sep-dec. 2010; 30(3): 147-153.

https://doi.org/10.3126/jnps.v30i3.3917

19. Mukhopadhyay P, Chaudhuri RN, Paul B. Hospital-based Perinatal Outcomes and Complications in Teenage Pregnancy in India. J Health Popul Nutr. 2010; 28(5): 494-500.

https://doi.org/10.3329/jhpn.v28i5.6158

PMid:20941901 PMCid:PMC2963772

20. Pathak P, Singh P, Kapil U, Raghuvanshi R. Prevalence of iron, vitamin A, and iodine deficiencies amongst adolescent pregnant mothers .Indian journal of pediatrics. 2013; 70: 299-301.
https://doi.org/10.1007/BF02723584

PMid:12793305

21. Anlaakuu P. Anaemia in pregnancy and associated factors: a cross sectional study of antenatal attendants at the Sunyani Municipal Hospital, Ghana. BMC Research Notes. 2017; 10: 402.

https://doi.org/10.1186/s13104-017-2742-2

PMid:28800737 PMCid:PMC5553653

22. Jahan K, Hossain M. Nature and Extent of Malnutrition in Bangladesh. Bangladesh National Survey, 1995-96, Dhaka, Bangladesh; Institute of Nutrition and FOOD science, University of Dhaka; 1998.

23. Centers for Disease Control and Prevention. Recommendations to prevent and control iron deficiency in the United States. MMWR Morb. Mortal Wkly Rep. 2018; 47:1-29.

24. Rusia U, Madan N, Agarwal N, Sikka M, Sood. Effect of maternal iron deficiency anaemia on foetal outcome. Indian J pathol Mcirobiol. 2015; 28: 273

25. Halberg L. Iron. In: JS Garrow, WPT James Eds. Human nutritional and Dietetics. London. Churchill Livingstone; 2012: 174-207. 